University of Wollongong

Research Online

Faculty of Engineering and Information

Faculty of Engineering and Information

Sciences - Papers: Part B

Sciences

2017

Secondary control of voltage \& current unbalance in a multi-bus microgrid using cooperative adjustment of Q- droop gains

\author{
Edward Smith \\ University of Wollongong, ejs760@uowmail.edu.au \\ Duane A. Robinson \\ University of Wollongong, duane@uow.edu.au \\ Phil Ciufo \\ University of Wollongong, ciufo@uow.edu.au
}

Follow this and additional works at: https://ro.uow.edu.au/eispapers1

Part of the Engineering Commons, and the Science and Technology Studies Commons

Research Online is the open access institutional repository for the University of Wollongong. For further information contact the UOW Library: research-pubs@uow.edu.au 


\title{
Secondary control of voltage \& current unbalance in a multi-bus microgrid using cooperative adjustment of Q- droop gains
}

\author{
Abstract \\ This paper describes a combined current and voltage unbalance compensation scheme for static power \\ converters on a multi-bus microgrid utilizing cooperative regulation on a sparse ad-hoc communication \\ network. The proposed control scheme is both robust to changing network conditions and corrects for \\ sub-optimal gain settings at each distributed generation unit. The scheme is based on local voltage and \\ current measurements by each distributed generation unit on the network, and utilizes a primary and \\ secondary control hierarchy. The scheme is then simulated using Matlab SimPowerSystem to \\ demonstrate operation of the compensation scheme and evaluate its performance. \\ Disciplines \\ Engineering | Science and Technology Studies

\section{Publication Details} \\ E. Smith, D. A. Robinson \& P. Ciufo, "Secondary control of voltage \& current unbalance in a multi-bus \\ microgrid using cooperative adjustment of Q- droop gains," in 2017 Australasian Universities Power \\ Engineering Conference (AUPEC), 2017, pp. 1-7.
}




\title{
Secondary Control of Voltage \& Current Unbalance in a Multi-bus Microgrid using Cooperative adjustment of $Q^{-}$Droop gains
}

\author{
Edward Smith, Duane A. Robinson, Philip Ciufo \\ Australian Power Quality \& Reliability Centre \\ University of Wollongong, NSW, Australia \\ ejs760@uowmail.edu.au
}

\begin{abstract}
This paper describes a combined current and voltage unbalance compensation scheme for static power converters on a multi-bus microgrid utilizing cooperative regulation on a sparse ad-hoc communication network. The proposed control scheme is both robust to changing network conditions and corrects for sub-optimal gain settings at each distributed generation unit. The scheme is based on local voltage and current measurements by each distributed generation unit on the network, and utilizes a primary and secondary control hierarchy. The scheme is then simulated using Matlab SimPowerSystem to demonstrate operation of the compensation scheme and evaluate its performance.
\end{abstract}

Index Terms-Microgrid, cooperative control, multi-agent system, voltage unbalance, negative sequence, secondary control, static converter

\section{INTRODUCTION}

The theory of microgrid operation and control is now a significant and well-developed research area. An area of growing interest is intelligent cooperative operating strategies for microgrids which can implement and allocate tasks at the local level, and do not rely on centralized control or communication. The requirements for microgrid control systems to manage harmonics, phase imbalance, unintentional islanding, faults and black start capability (system restoration) are some examples. Techniques for voltage and frequency control in microgrids is well represented in the literature, the ability of individual units or clusters to share tasks which relate to other aspects of grid operation, particularly power quality, is less well developed. The focus of this paper is unbalance.

International standards generally limit the acceptable voltage unbalance to $2-3 \%$ depending on the jurisdiction [1], and while methods for power sharing among distributed converters in islanded grids are well established, sharing of non-linear load current or unbalanced load current is less well developed. Negative sequence output current degrades the real power output capability of static converters and impacts the rating of protection devices.

Static power electronic converters are pervasive on the electricity network, and increasingly the primary method of power conversion for renewable energy and energy storage.
As such, it is considered normal that operators of the grid have interest in the scope for static distributed generation (DG) units to assist in regulation of power quality. Existing compensation schemes for current sharing and voltage unbalance correction have been proposed in [2-7], however disadvantages of these schemes include:

a) primary control schemes without secondary correction are fast-acting and autonomous however cannot adapt to changed network conditions;

b) secondary compensation schemes are slower acting and may depend on continuous communication links; and

c) demonstration is limited to a single bus microgrid.

\section{SIMPLIFIED MODEL OF UNBALANCE IN MICROGRIDS}

The primary control scheme for unbalance compensation utilized in this paper is based on a simple unbalanced impedance network supplied from a three-phase voltage source as shown in Figure 1. Using symmetrical components, the positive and negative sequence currents are given by phasor equations (1)-(2). As shown in [3,12], and assuming the voltage unbalance is less than $3-5 \%$, the negative sequence current supplying the network depends primarily on the positive sequence voltage and the unbalance admittance as shown by (4)-(5), where the terms $V^{-} \cdot Y$ and $V^{-} \cdot Y_{u}$ can usually be neglected, $a=\frac{-1}{2}+\frac{\sqrt{3}}{2} j$ and $Y_{u}$ is the unbalance load admittance value. This simplification is utilized for the control scheme to be described.

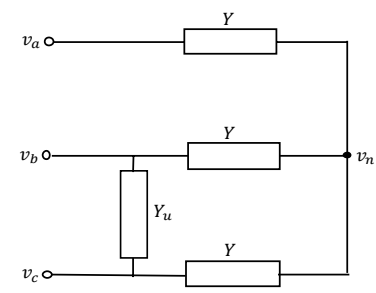

Figure 1. Impedance network for unbalance analysis

A simple common bus microgrid is shown in Figure 2, consisting of two DG converter units connected through an impedance to a load. $E_{n}^{-}$and $I_{n}^{-}$are the unbalance components for output voltage and current respectively. 


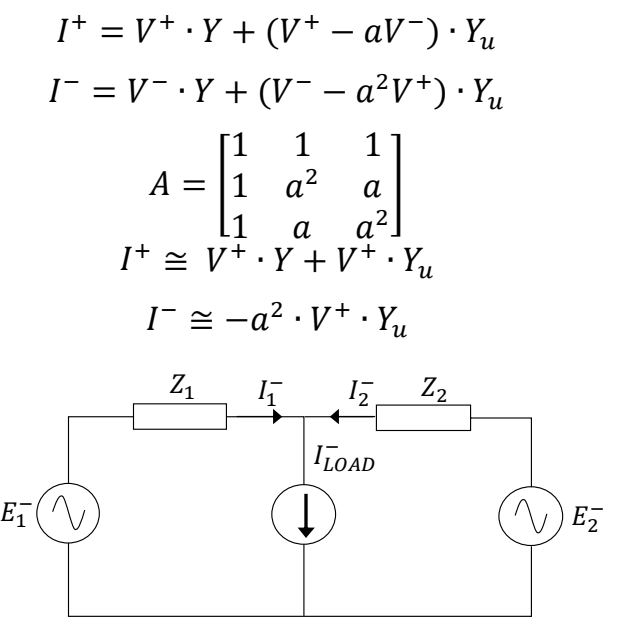

Figure 2. Negative sequence equivalent circuit of simplified microgrid

Using the approximation in (5), the load current $I_{L O A D}^{-}$in Figure 2 can be considered a current source for a constant unbalanced load. The following derivation for the negative sequence reactive power is described in [7], and is based on the instantaneous power theory [9]. For a sinusoidal voltage source, the time dependent functions for voltage and current are given by (6)-(11). From these, the instantaneous power expression is derived as shown in (12)-(14)

$$
\begin{gathered}
E=\sqrt{2} \sin \omega t \\
E=\sqrt{2} \sin \left(\omega t-120^{\circ}\right) \\
E=\sqrt{2} \sin \left(\omega t+120^{\circ}\right) \\
i_{a}=\sqrt{2}\left(I^{+} \sin \left(\omega t+\theta^{+}\right)+I^{-} \sin \left(\omega t+\theta^{-}\right)\right) \\
i_{b}=\sqrt{2}\left(I^{+} \sin \left(\omega t-\theta^{+}\right)+I^{-} \sin \left(\omega t+\theta^{-}\right)\right) \\
i_{c}=\sqrt{2}\left(I^{+} \sin \left(\omega t+\theta^{+}\right)+I^{-} \sin \left(\omega t-\theta^{-}\right)\right)
\end{gathered}
$$

As seen in (13), the instantaneous power includes a constant component and a time-varying component.

$$
\begin{gathered}
p=e_{a} i_{a}+e_{b} i_{b}+e_{c} i_{c} \\
p=3 E I^{+} \cos \theta^{+}-3 E I^{-} \cos \left(2 \omega t+\theta^{-}\right) \\
=p^{+}+p^{ \pm}
\end{gathered}
$$

Using the interpretation in $[7,13],(15)$ is the negative sequence reactive power, with magnitude given by (16).

$$
\begin{gathered}
p^{ \pm}=3 E I^{-} \cos \left(2 \omega t+\theta^{-}\right) \\
Q^{-}=3 E I^{-}
\end{gathered}
$$

Referring to Figure 2, using Kirchhoff's law we can derive the following relationships for the negative sequence current contribution of each DG converter unit as (20). Adjusting $E_{1}^{-}$ or $E_{2}^{-}$the current sharing ratio is changed.

$$
\begin{gathered}
E_{1}^{-}+I_{1}^{-} Z_{1}=E_{2}^{-}+I_{2}^{-} Z_{2} \\
I_{1}^{-}+I_{2}^{-}=I_{L O A D}^{-} \\
I_{1}^{-}=-\left(\frac{1}{Z_{1}+Z_{2}}\right) E_{1}^{-}+\left(\frac{E_{2}^{-}+I_{L O A D}^{-} Z_{2}}{Z_{1}+Z_{2}}\right)
\end{gathered}
$$

$$
I_{1}^{-}=\frac{Z_{2}}{Z_{1}} I_{2}+\frac{E_{2}^{-}-E_{1}^{-}}{Z_{1}}
$$

\section{REVIEW OF EXISTING CONTROL SCHEMES}

\section{A. Self-regulating Strategies for Harmonic and Unbalance} Current Sharing

Active control schemes for load sharing, both for active and reactive power regulation, in islanded microgrids are well developed. Several authors have also developed proposals for sharing of non-linear loads and compensation of voltage harmonics in microgrids using static DG inverters [2-7]. Introducing a designed output (or virtual) impedance which is responsive to harmonic voltage components, and which therefore can be tuned to enable sharing of non-linear loads between inverters is one approach [15, 16]. However, introducing output compensation without regard for other compensation actions of paralleled DG inverters in an islanded microgrid can make the situation more unstable, not less [12].

Cooperative control of voltage harmonics or non-linear loads in microgrids is addressed in [14, 17] using adapted droops. This theory is partially derived from active shunt filter control theory for distribution feeders introduced by [18-19]. Both these approaches are based on droop control principles, where a harmonic gain coefficient is adjusted based on a measured harmonic distortion metric, normally taken at the point of grid coupling, and harmonic compensation current is injected as an additional signal input to the current reference control loop. In this way, an inverse linear dependency between calculated harmonic power output and harmonic gain input is established in a similar way that a conventional power frequency droop characteristic functions. The effect is that the converter acts as a variable conductance for harmonics, or negative sequence current (unbalance).

The equations for deriving the compensation current signal from the conductance $G$ command and extracted negative sequence output voltage given by $E_{o}^{-}$are shown for unbalance compensation in (21)-(23). Sharing ratios between $D G_{i}$ are established using gain values $u_{i}$, where $Q_{0}^{-}$is the rated or max. unbalance output and with the resulting steadstate sharing in principle according to (23).

The compensating current signal is summed with the primary voltage controller output (current controller ref. input) as shown in Figure 5. [16] notes that using the current controller input as the point of injection may be inappropriate for the reason that it is regarded as a disturbance by the voltage controller, and [4] implements a similar scheme for the voltage reference signal, in a stationary rather than rotating reference frame.

$$
\begin{gathered}
i_{c}^{-}=G^{-} \cdot E_{o}^{-} \\
G^{-}=G_{0}^{-}-u_{i}\left(Q_{i 0}^{-}-Q^{-}\right) \\
u_{1} Q_{10}^{-}=u_{2} Q_{20}^{-}=\cdots=u_{n} Q_{n 0}^{-}
\end{gathered}
$$

\section{B. Secondary Compensation of Voltage Unbalance}

Utilization of static DG for voltage unbalance compensation on a microgrid is address in $[3-4,20-21]$ as 
secondary control scheme. In [17], a Sensitive Load Bus (SLB) is nominated for the microgrid and a secondary compensation controller introduced to regulate both the voltage harmonics and unbalance (negative sequence) at the SLB by having each DG inject compensating currents according to a sharing strategy based on the capacity of each unit to supply harmonic and unbalance current components.

An important feature of this control strategy is that DG units can compensate voltage distortion which is elsewhere (non-local) on the network. An unbalance measurement unit (PQ meter) at the SLB sends the voltage harmonic and negative sequence magnitudes as DC values down a low bandwidth communication (LBC) link to the Secondary Controller, which calculates the required references for each DG unit in the microgrid to use as the compensation target value. The Compensation Effort Controller then determines the share of each unit's compensation current. The measurement block at the Sensitive Load Bus transforms the measured harmonic and sequence components into directquadrature values for communication as dc values along the LBC link to a central secondary controller which calculates the reference harmonic distortion index components for communication again as de values along an LBC link to each DG unit on the microgrid.

The primary controls of the static converter are implemented in a stationary reference frame. The reference indices are passed through $d q \rightarrow \alpha \beta$ transformations, each using $\pm n \omega$ multiples of the PLL-extracted angular frequency, and the resulting ac components summed with the voltage control reference.

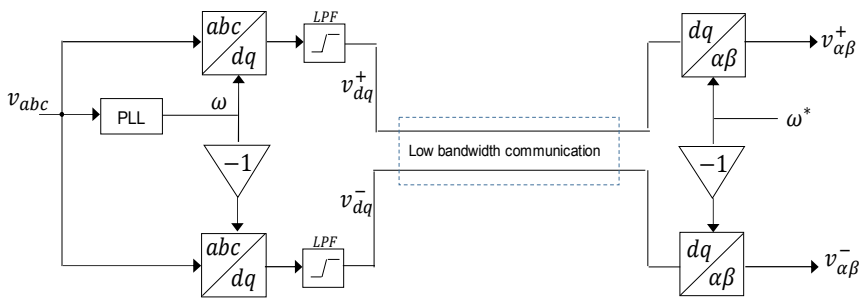

Figure 3. Low-Bandwidth transmission of ac sequence components information for a Secondary Compensation Scheme

The advantages of a stationary reference frame implementation are described in the next Section, and while this scheme has elements of 'cooperative' control, it relies on a continuous communication link between controllers and centralised secondary controller.

\section{Multi-Agent Techniques for Cooperative Control}

Use of agent-based distributed control techniques in microgrid research has wide application, and includes for example secondary voltage and frequency control [18], [19], power flow control and network utilization [20], fault location, isolation, and restoration [21], and economic dispatch [22]. The two distinct classes of multi-agent problems are a) cooperative regulation problems, and b) cooperative tracking problems. The applications in power research are generally restricted to secondary control and coordination or protection functions, with applications in power quality to date limited. A dynamic consensus algorithm is utilized in [3] as a secondary control strategy to improve negative sequence current sharing amount static DG in a microgrid, which is an example of a cooperative regulator.

\section{SECONDARY CONTROL OF VOLTAGE AND CURRENT UNBALANCE USING DROOP GAINS}

\section{A. Formulation of Q-Droop Equations}

The $Q^{-}$control law for primary unbalance compensation is shown in (24), based on the unbalance model developed in Section II. This is similar to the control law described in [7], with modifications such that: i) the compensating signal is injected into the outer voltage control loop rather than the inner current control loop; and ii) the droop constants (gains) are subject to a secondary adjustment process as described in the next Section.

The control law shown in (24) suggests a technique for primary compensation of negative sequence current sharing for a network of static power converters, however practical implementation on multi-bus network would often result in suboptimal performance as will be described.

$$
E_{n}^{-}=a_{n}+b_{n}\left(Q_{n 0}^{-}-Q_{n}^{-}\right)
$$

Referring to the network shown in Figure 2, the expression for the ratio of negative sequence output current is shown in (25). By substituting the control law from (24) into this expression, we can establish for example the conditions under which this ratio equates to the ratio of unit rated negative sequence power output (27). That is, the ratio of the droop constant $b_{n}$ equates to the ratio of rated negative sequence output power, and the line impedance values are equal.

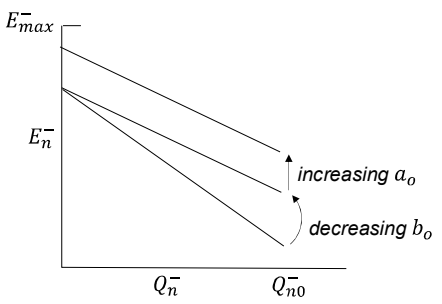

Figure 4. Effect of adjusting droop constants

$$
\begin{gathered}
\frac{I_{2}^{-}}{I_{1}^{-}}=\frac{E_{1}^{-}-E_{2}^{-}+I_{L}^{-} Z_{1}}{E_{2}^{-}-E_{1}^{-}+I_{L}^{-} Z_{2}} \\
\frac{b_{1}\left(Q_{10}^{-}-Q_{1}^{-}\right)-b_{2}\left(Q_{20}^{-}-Q_{2}^{-}\right)+I_{L}^{-} Z_{1}}{b_{2}\left(Q_{20}^{-}-Q_{2}^{-}\right)-b_{1}\left(Q_{10}^{-}-Q_{1}^{-}\right)+I_{L}^{-} Z_{2}}=\frac{Q_{20}^{-}}{Q_{10}^{-}} \\
\text {As } c \rightarrow \frac{Q_{10}^{-}}{Q_{20}^{-}} \text {and } Z_{1} \rightarrow Z_{2} \text { then } \frac{Q_{1}^{-}}{Q_{2}^{-}} \rightarrow \frac{Q_{10}^{-}}{Q_{20}^{-}}
\end{gathered}
$$

The effect of adjusting the droop equation constants $b_{0}$ and $a_{0}$ is shown in Figure 4. The constant $b_{n}$ may be adjusted to improve the negative sequence current output sharing, and the constant $a_{n}$ adjusted to reduce the voltage unbalance at the DG bus. The negative sequence voltage $E_{n}^{-}$is injected as an additional signal input for the voltage control loop error amplifier, as shown in Figure 5 as $v_{c}^{-}$. However, practical implementation of (24) on a multi-bus network would result in suboptimal performance due to non-symmetric network 
impedances, and difficulty in establishing correct gain settings without prior knowledge of other network parameters.

\section{B. Secondary Adjustment of $Q^{-}$Droop Gains}

Based on multi-agent coordination, secondary adjustment of the control constants is possible to restore or correct for sub-optimal performance with minimal communication overhead, and guaranteed convergence to equilibrium.

The following definitions are required; the per unit negative sequence current is $\hat{I}_{n}^{-}=\frac{I_{n}^{-}}{I_{n 0}^{-}}$where $I_{n 0}^{-}$is the maximum rated negative sequence current output, and the voltage unbalance factor $V U F=\frac{V^{-}}{V^{+}} \times 100$, where $V^{-}$and $V^{+}$are the negative and positive sequence voltages respectively. All voltage and current variables are rms values.

The secondary control laws for the cooperative adjustment of the droop constants in (24) are shown in (28)-(31), where $\hat{I}_{r e f}^{-}$is the common (consensus) negative sequence current reference, and similarly $\Delta a_{i}^{r e f}$ is a voltage unbalance factor offset reference. Both reference values are calculated in discrete iterations using a consensus algorithm based on adhoc information sharing among agents in the microgrid. This algorithm is described in the next Section.

In principle, compensation based on several performance metrics can be implemented using this scheme. The secondary adjustment is designed to achieve the following:

a) convergence of the p.u. -ve sequence output current to the microgrid average value, using the rated negative sequence output power as a base for each static DG unit

b) reduction of the voltage unbalance factor at each point of bus coupling equal to or below an established threshold limit

The consensus algorithm is shown in (30)-(31), where $m_{i j}$ and $w_{i j}$ are the edge weights allocated to adjacent nodes in the communication network, and are topology dependent. This is described in the next Section. Proportional and integral gains are $K_{P}$ and $K_{I}$ are included for closed loop performance. $\triangle V U F$ is the error between the maximum allowable unbalance factor (e.g. 3\%) and the calculated unbalance factor, using the measured output voltage at each converter. As shown in (32), the value of $\Delta V U F$ is set to zero where the DG output voltage unbalance is within the limits.

$$
\begin{gathered}
b_{n}=b_{0}+\left(\hat{I}_{r e f}^{-}-\hat{I}_{n}^{-}\right)\left(K_{p}+\frac{K_{I}}{s}\right) \\
a_{n}=a_{0}+\left(\Delta a_{i}^{r e f}\right)\left(K_{p}+\frac{K_{I}}{s}\right) \\
\hat{I}_{r e f}^{-}(k+1)=\hat{I}_{r e f}^{-}(k)+c K \sum_{j \in N} m_{i j}\left(\hat{I}_{i}^{-}-\hat{I}_{j}^{-}\right) \\
\Delta a_{i}^{r e f}(k+1)=\Delta a_{i}^{r e f}(k)+c K \sum_{j \in N} w_{i j}\left(\Delta a_{i}-\Delta a_{j}\right)
\end{gathered}
$$

The principle of operation for the voltage unbalance compensation is that nodes which exceed the limit will accumulate a distributed average unbalance offset reference to all other nodes, and thus all converters cooperate in reduction of voltage unbalance in the network.

$$
\Delta a_{i}= \begin{cases}C, & \Delta V U F_{i}>0 \\ 0, & \Delta V U F_{i}<0\end{cases}
$$

where $C=\Delta V U F_{i}$ or a constant for hysteresis control, and $v_{c}^{-}=E_{n}^{-}$is the compensation signal added to the primary voltage control loop.

The secondary cooperative control action consists of two stages, the information discovery phase $T_{I}$ where the reference values converge to the average value, and the secondary control phase $T_{S}$, where the current or voltage is controlled to the reference value. Given that normally $T_{S} \gg$ $T_{I}$ convergence would be expected though the proof is omitted.

\section{Stationary Reference Frame Converter Model}

The static power converter model is shown in Figure 5, and the control block diagram for the secondary controller shown in Figure 6. The converter control model utilizes the stationary reference frame transformation $a b c \rightarrow \alpha \beta$ and proportional resonant (PR) controllers for the inner current and voltage control loops. This has the following key advantages over a rotating reference frame control architecture; i) control of unbalanced current does not require independent sequence controllers, and can be controlled using a single PR-block, and ii) harmonic compensators can be implemented through parallel tuned PR-blocks, each tuned to the required harmonic frequencies. This control architecture therefore supports generic grid conditions, faults and disturbances. Refer to [22-24] for detailed analysis and implementation of stationary reference frame DG models.

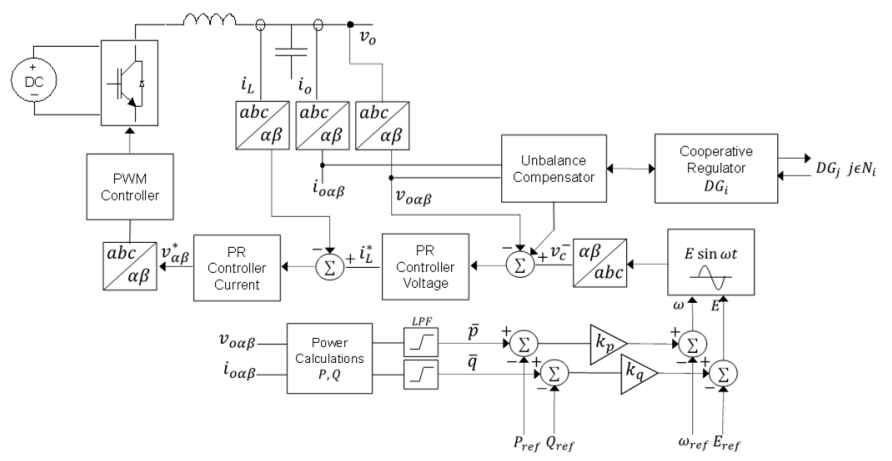

Figure 5. Three-phase converter control block diagram

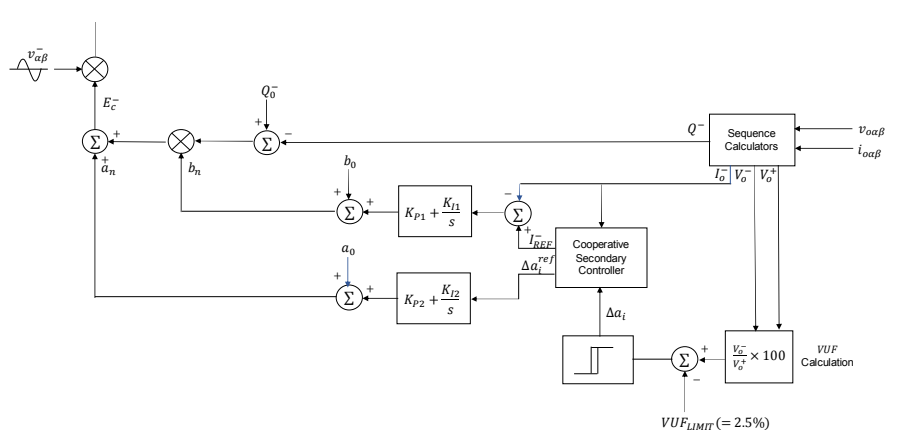

Figure 6. Unbalance compensator control block diagram 


\section{Cooperative Regulator for Secondary Control}

Design of cooperative controllers based on multi-agent theory and consensus problems is a significant research area, and a simple model is utilized in this paper. Multi-agent theory provides a comprehensive theoretical framework for analysis of networked control systems that includes rigorous definitions of performance, stability and robustness $[9,10]$. The cooperative secondary regulator for the converter is shown in Figure 7.

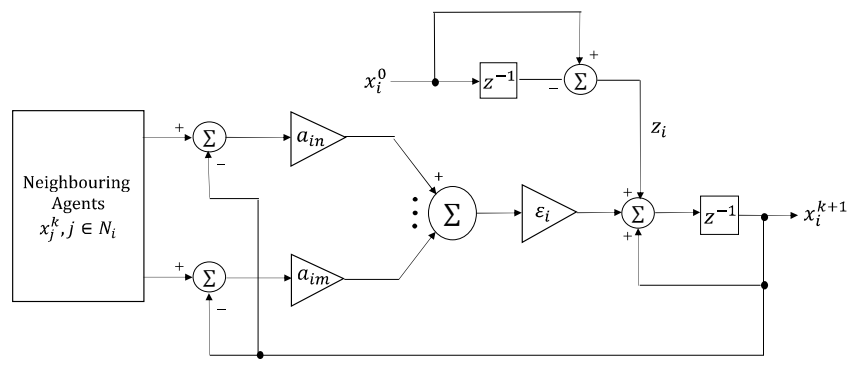

Figure 7. Coop. regulator, distributed averaging for $\mathrm{N}$ agents using (39)

Consensus problems are based on the application of Graph Theory where each node represents an agent with some dynamic behaviour. A directed graph, or digraph, $G=$ $(V, E, A)$ is shown below, where the set of nodes are $V=$ $\left\{v_{1}, v_{2}, \cdots, v_{n}\right\}$, the set of directed arcs or edges $E$ from $v_{i}$ to $v_{j}$ given by $\left(v_{i}, v_{j}\right)$, and the weights associated with each edge $0 \leq a_{i j} \leq 1$ described by an adjacency matrix $A=\left[a_{i j}\right]$ for $G$. Each node has an associated set of neighbours $N_{i}=$ $\left(v_{j}:\left(v_{j}, v_{i}\right) \in E\right)$. Each Graph $G$ has an associated Laplacian matrix $L$. The eigenvalues of $L$, denoted $\lambda_{n}$, are particularly significant since they determine the dynamics of the multigent system $[25,26]$.

Considering the case of each node having state dynamics $\dot{x}_{i}=f\left(x_{i}, u_{i}\right)$, then the consensus problem consists of selecting control inputs $u_{i}$ for each node where each control depends on the state of each node and its set of nearest neighbours (33), such that from given initial conditions the states of all nodes converge to the same consensus value (34).

$$
\begin{gathered}
u_{i}=k_{i}\left(x_{i}, x_{j 1}, \cdots, x_{j m}\right) \\
x_{i}=x_{j}=c, \quad \forall i, j
\end{gathered}
$$

The network topology for the reference microgrid is shown in Figure 8. Considering a wireless network, connections may be ad-hoc and the conditions for convergence based on several possible protocols is given for example in [30].

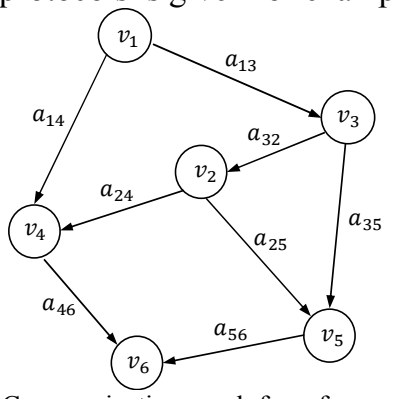

Figure 8. Communication graph for reference microgrid
In this application, the consensus algorithm is a distributed calculator of the reference value, and used for information discovery. In contrast, the consensus problem for coupled converter states is complex, given non-linear microgrid dynamics. Conditions for convergence of states for linear time-invariant and other dynamics is given in [27], [31].

The state dynamic equation of a discrete time cooperative regulator is shown in (35), using the input control law $u_{i}=$ $\sum_{j \epsilon N} a_{i j}\left(x_{i}-x_{j}\right)$, the accumulation of neighbouring state errors. The control laws given in (30) and (31) are equivalent to (35), and used for calculation of the secondary reference values for negative sequence current and voltage unbalance. The conditions for convergence and steady state value depend on the graph topology and communication weight matrix (or adjacency matrix) design and update rules.

For a first order discrete time system as shown in (35) the equilibrium value is given by (36).

$$
\begin{gathered}
x_{i}(k+1)=x_{i}(k)+\sum_{j \in N} a_{i j}\left(x_{i}-x_{j}\right) \\
\bar{x}=\sum_{i} p_{i} x_{i}(0)
\end{gathered}
$$

where $\left[p_{1} p_{2} \ldots p_{N}\right]^{T}$ is the left eigenvector of the Perron matrix of the graph $G$, and $P=I-\epsilon L$ where $I$ is the identity matrix and $\epsilon$ the step size. For a graph $G$, conditions for convergence require the graph to contain a spanning tree, and (36) is interpreted as the weighted average of initial state values. Theorems for convergence and stability of discrete time consensus problems utilize results from matrix theory, such as Perron-Frobenius [31].

Several algorithms can be used to establish online appropriate weights for the adjacency matrix (or communication matrix), such as for example the Metropolis Method [30]. Figure 7 shows the discrete time control block implementation of a cooperative regulator, where an auxiliary input $z_{i}$, is used to update the initial value $x_{i}(0)$.

The consensus algorithm can be demonstrated to converge also under switching topologies and with communication time delays [27]. Communication matrix update rules for fast convergence and protocol design consideration for practical implementations, for example on wireless networks, are not considered in this paper. Implementation considerations include, for example, communication time delays (also synchronous/asynchronous update), signal interference, and cost of communication resources, refer to $[10,27]$. Other algorithms for fast asynchronous distributed averaging include [32], or dynamic consensus algorithm (DCA), however [33] notes this algorithm does not always guarantee convergence.

\section{E. Reference MicroGrid}

The 6-bus microgrid used for simulation is shown in Figure 9. The microgrid is initially connected to an external grid through the point of common coupling (PCC), and an unbalance load L5 is switched on during the simulation to test the operation of the unbalance controllers. 


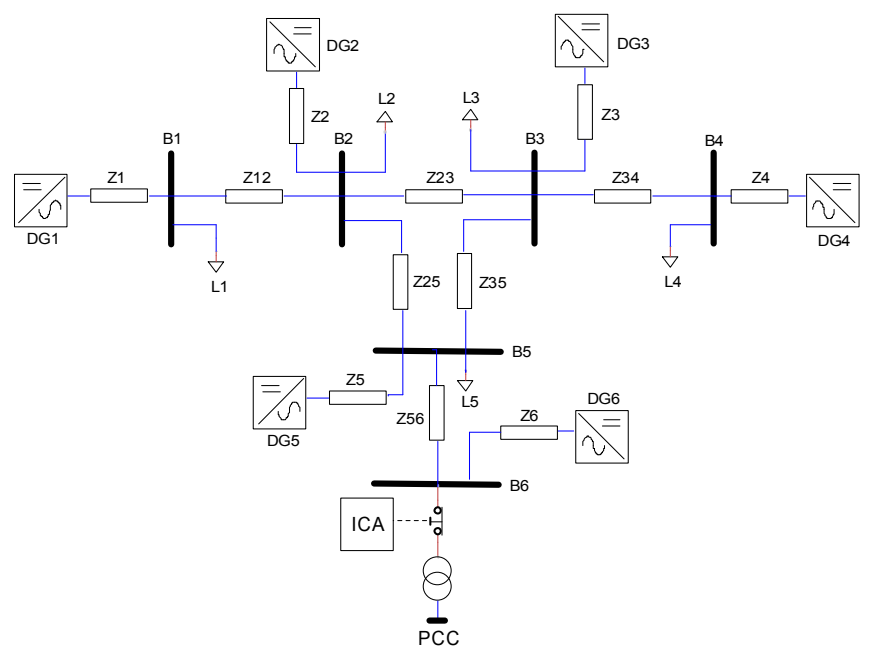

Figure 9. Reference 6-bus microgrid for simulation. Unbalance load at B5.

\section{Simulation RESUlts}

The results of the simulation study on the reference grid (Figure 9) are shown in Figures 10-12. The power system model is implemented in Matlab SimPowerSystems as a low voltage ac three-wire, three phase network (no zero sequence). The line impedances shown in Figure 9 use arbitrary resistance and inductance values to model a nonsymmetric network. The microgrid is initially connected to an external mains ac source to simulate the grid, then is islanded from the grid at $1.7 \mathrm{~s}$. Constant linear loads are connected and shown as L1-L4 in Figure 9, and an unbalance load L5 is introduced during the simulation. The initial droop settings are shown in Table I.

Table I. Droop control settings

\begin{tabular}{ccccc}
\hline \hline DG UNIT & $\begin{array}{c}\text { RATED } \\
\text { POWER }\end{array}$ & $\begin{array}{c}\text { NOM. } \\
\text { VOLTAGE }\end{array}$ & $\begin{array}{c}\text { NOM. } \\
\text { FREQUENCY }\end{array}$ & $\begin{array}{c}Q^{-} \text {INITIAL DROOP } \\
\text { CONTROL SETTINGS }\end{array}$ \\
\hline DG1 & 100KVA & $415 \mathrm{~V}$ & $50 \mathrm{~Hz}$ & $-2.50 \mathrm{E}-5$ \\
DG2 & 90KVA & $415 \mathrm{~V}$ & $50 \mathrm{~Hz}$ & $-2.86 \mathrm{E}-5$ \\
DG3 & 80KVA & $415 \mathrm{~V}$ & $50 \mathrm{~Hz}$ & $-3.33 \mathrm{E}-5$ \\
DG4 & 70KVA & $415 \mathrm{~V}$ & $50 \mathrm{~Hz}$ & $-4.00 \mathrm{E}-5$ \\
DG5 & 60KVA & $415 \mathrm{~V}$ & $50 \mathrm{~Hz}$ & $-5.00 \mathrm{E}-5$ \\
DG6 & 50KVA & $415 \mathrm{~V}$ & $50 \mathrm{~Hz}$ & $-6.67 \mathrm{E}-5$ \\
\hline \hline
\end{tabular}

The following steps describe the simulation process sequence. The microgrid is islanded at $1.7 \mathrm{~s}$, and the six static DG converter units supply output power according to their primary droop controller settings.

a) at $3 \mathrm{~s}$ an unbalance load is switched onto Bus 5. The increase in -ve sequence current is shown in Figure 11.

b) at $4 \mathrm{~s}$ the $Q^{-}$primary droop controllers are activated on all units, resulting in some improvement in unbalance current output sharing.

c) at $6 \mathrm{~s}$ the secondary cooperative controllers for adjustment of $Q^{-}$droop gains $b_{0}$ are activated on all units, and after several seconds the -ve sequence output current converges to the optimal shared value.

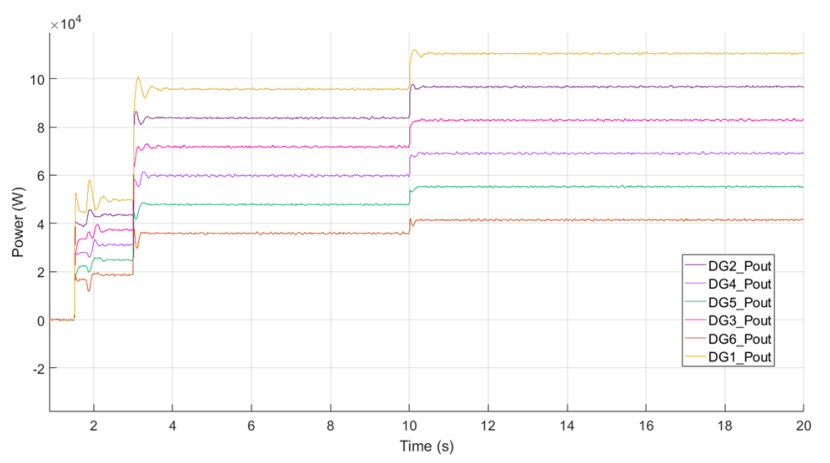

Figure 10. Output power from each DG converter. Unbalance load switched in at $3 \mathrm{~s}$ and $10 \mathrm{~s}$ load steps.

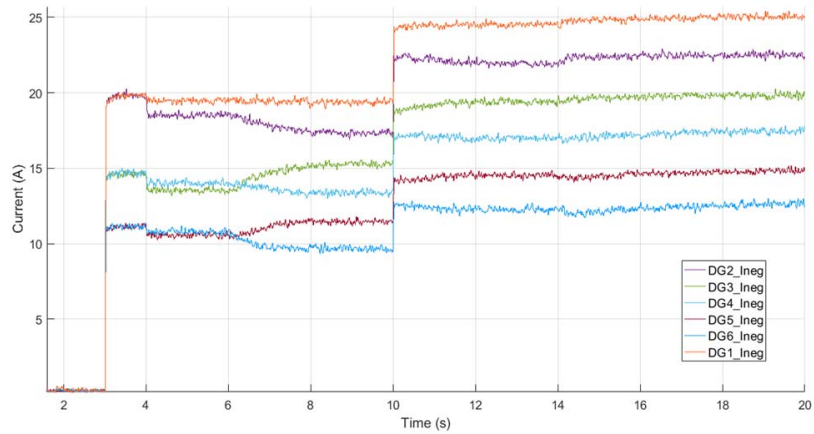

Figure 11. Negative sequence current output from each DG converter. Unbalance load is switched in at $3 \mathrm{~s}$ and $10 \mathrm{~s}$ load steps.

An additional unbalance load step is introduced at $10 \mathrm{~s}$ which increases the voltage unbalance at the connection Bus of two static DG units (DG1 and DG2) above the allowable limit of $2.5 \%$. The adjustment of the $Q^{-}$droop gains $a_{0}$ is then activated at $14 \mathrm{~s}$, and after several seconds the voltage unbalance converges to within the allowable value.

d) at $10 \mathrm{~s}$ an additional unbalance load step is switched on at Bus 5, and the increase in -ve sequence current is shown in Figure 11.

e) at $14 \mathrm{~s}$, secondary cooperative adjustment of the $Q^{-}$ droop gains $a_{0}$ is activated and after several seconds the voltage unbalance $(V U F)$ reduces to within the allowable value, as shown on Figure 12.

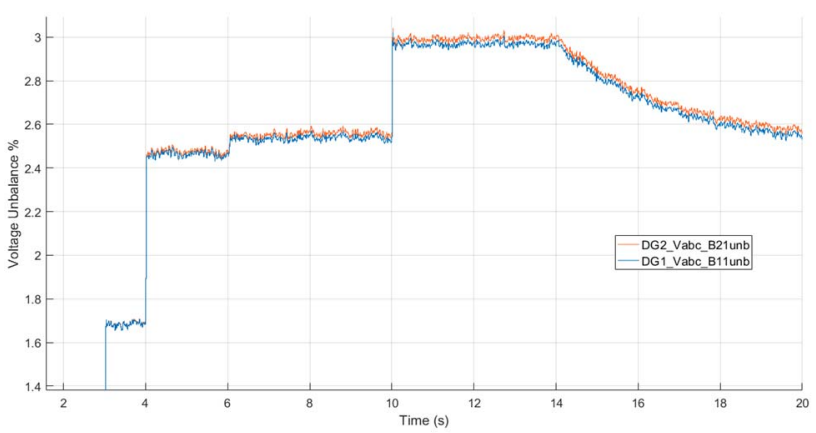

Figure 12. Voltage unbalance (\%) at output of DG1 \& DG 2. Limit of $2.5 \%$ exceeded at $10 \mathrm{~s}$ unbalance load step, and secondary adjustment at $14 \mathrm{~s}$. 


\section{CONCLUSION}

This paper has described a combined current and voltage unbalance compensation scheme for static power converters on a multi-bus microgrid, utilizing cooperative regulation on a sparse ad-hoc communication network. The proposed control scheme is both robust to changing network conditions and corrects for sub-optimal gain settings at each distributed generation unit. The scheme has been successfully implemented in simulation using Matlab SimPowerSystem to demonstrate operation of a multi-bus reference microgrid. Scope for further research includes hardware implementation, and conditions for convergence and dynamic stability of cooperative agent-based control will be further investigated.

\section{REFERENCES}

[1] A. von Jouanne, "Assessment of voltage unbalance," IEEE Trans. Power Deliv., vol. 17, no. 4, pp. 1176-1177, 2002.

[2] M. Hamzeh, S. Member, H. Karimi, and H. Mokhtari, "A New Control Strategy for a Multi-Bus MV Microgrid Under Unbalanced Conditions," vol. 27, no. 4, pp. 2225-2232, 2012.

[3] L. Meng, X. Zhao, F. Tang, M. Savaghebi, T. Dragicevic, J. C. Vasquez, and J. M. Guerrero, "Distributed Voltage Unbalance Compensation in Islanded Microgrids by Using a Dynamic Consensus Algorithm," IEEE Trans. Power Electron., vol. 31, no. 1, pp. 827838,2016

[4] S. Mehdi, A. Jalilian, J.C. Vasquez, J.M. Guerrrero, "Secondary Control Scheme for Voltage Unbalance Compensation in an Islanded," IEEE Trans. Smart Grid, vol. 3, no. 2, pp. 1-12, 2012.

[5] X. Yuan, W. Merk, H. Stemmler, and J. Allmeling, "Stationary-frame generalized integrators for current control of active power filters with zero steady-state error for current harmonics of concern under unbalanced and distorted operating conditions," IEEE Trans. Ind. Appl., vol. 38, no. 2, pp. 523-532, 2002.

[6] M. Hojo, Y. Iwase, T. Funabashi, and Y. Ueda, "A method of threephase balancing in microgrid by photovoltaic generation systems," 2008 13th Int. Power Electron. Motion Control Conf. EPE-PEMC 2008, pp. 2487-2491, 2008.

[7] P. T. Cheng, C. A. Chen, T. L. Lee, and S. Y. Kuo, "A cooperative imbalance compensation method for distributed-generation interface converters," IEEE Trans. Ind. Appl., vol. 45, no. 2, pp. 805-815, 2009.

[8] D. J. Glover, S. S. Mulukutla, and J. O. Thomas, Power system analysis and design, vol. 1. Boston, MA, USA: Cengage Learning, 2012.

[9] H. Akagi, E. H. Watanabe, and M. Aredes, "The Instantaneous Power Theory," Instant. Power Theory Appl. to Power Cond., pp. 41-107, 2007.

[10] J. M. Guerrero, L. G. De Vicuña, J. Matas, J. Miret, and M. Castilla, "Output impedance design of parallel-connected UPS inverters," IEEE Int. Symp. Ind. Electron., vol. 2, no. 4, pp. 1123-1128, 2004.

[11] J. M. Guerrero, J. C. Vásquez, J. Matas, M. Castilla, and L. García de Vicuna, "Control strategy for flexible microgrid based on parallel lineinteractive UPS systems," IEEE Trans. Ind. Electron., vol. 56, no. 3, pp. 726-736, 2009.

[12] U. Borup, F. Blaabjerg, and P. N. Enjeti, "Sharing of nonlinear load in parallel-connected three-phase converters," IEEE Trans. Ind. Appl., vol. 37 , no. 6 , pp. $1817-1823,2001$

[13] T. L. Lee and P. T. Cheng, "Design of a new cooperative harmonic filtering strategy for distributed generation interface converters in an islanding network," IEEE Trans. Power Electron., vol. 22, no. 5, pp. 1919-1927, 2007.

[14] H. Akagi, H. Fujita, K. Wada, A. P. Distribution, and L. Simulator, "A Shunt Active Filter Based on Voltage Detection for Harmonic Termination of a Radial Power Distribution Line," pp. 1393-1399, 1998.
[15] P. Jintakosonwit, H. Fujita, H. Akagi, and S. Ogasawara, "Implementation and performance of cooperative control of shunt active filters for harmonic damping throughout a power distribution system," Conf. Rec. 2002 IEEE Ind. Appl. Conf. 37th IAS Annu. Meet. (Cat. No.02CH37344), vol. 1, pp. 51-58, 2002.

[16] M. Savaghebi, J. M. Guerrero, A. Jalilian, and J. C. Vasquez, "Experimental evaluation of voltage unbalance compensation in an islanded microgrid," Proc. - ISIE 20112011 IEEE Int. Symp. Ind. Electron., pp. 1453-1458, 2011.

[17] M. Savaghebi, A. Jalilian, J. C. Vasquez, and J. M. Guerrero, "Secondary control for voltage quality enhancement in microgrids," IEEE Trans. Smart Grid, vol. 3, no. 4, pp. 1893-1902, 2012.

[18] A. Bidram, S. Member, A. Davoudi, F. L. Lewis, J. M. Guerrero, and S. Member, "Distributed Cooperative Secondary Control of Microgrids Using Feedback Linearization," vol. 28, no. 3, pp. 34623470, 2013.

[19] M. S. Mahmoud, Control and Optimization of Distributed Generation Systems, Spinger 2015.

[20] H. Xin, Z. Qu, J. Seuss, and A. Maknouninejad, "A self-organizing strategy for power flow control of photovoltaic generators in a distribution network," IEEE Trans. Power Syst., vol. 26, no. 3, pp. 1462-1473, 2011.

[21] Y. Xu and W. Liu, "Novel multiagent based load restoration algorithm for microgrids," IEEE Trans. Smart Grid, vol. 2, no. 1, pp. 140-149, 2011.

[22] H. Liang, B. J. Choi, A. Abdrabou, W. Zhuang, and X. Shen, "Decentralized economic dispatch in microgrids via heterogeneous wireless networks," IEEE J. Sel. Areas Commun., vol. 30, no. 6, pp. 1061-1074, 2012.

[23] J. C. Vasquez, J. M. Guerrero, M. Savaghebi, and R. Teodorescu, "Modeling, analysis, and design of stationary reference frame droop controlled parallel three-phase voltage source inverters," 8th Int. Conf. Power Electron. - ECCE Asia "Green World with Power Electron. ICPE 2011-ECCE Asia, pp. 272-279, 2011.

[24] D. G. Holmes, T. A. Lipo, B. P. McGrath, and W. Y. Kong, "Optimized design of stationary frame three phase AC Current regulators," IEEE Trans. Power Electron., vol. 24, no. 11, pp. 2417 2426, 2009.

[25] F. J. Rodríguez, E. Bueno, M. Aredes, L. G. B. Rolim, F. A. S. Neves, and M. C. Cavalcanti, "Discrete-time implementation of second order generalized integrators for grid converters," Proc. - 34th Annu. Conf. IEEE Ind. Electron. Soc. IECON 2008, no. 1, pp. 176-181, 2008.

[26] L. Qiu, B. Bernhardsson, A. Rantzer, E. J. Davison, P. M. Young, and J. C. Doyle, "A formula for computation of the real stability radius," Automatica, vol. 31, no. 6, pp. 879-890, 1995.

[27] R. Olfati-Saber and R.M. Murray, "Consensus Problems in Networks of Agents with Switching Topology and Time-Delays," IEEE Trans. Automat. Contr., vol. 49(9), no. 9, pp. 1520-1533, 2004.

[28] H. Zhang, F. L. Lewis, and A. Das, "Optimal Design for Synchronization of Cooperative Systems: State Feedback, Observer and Output Feedback," IEEE Trans. Automat. Contr., vol. 56, no. 8, pp. 1948-1952, 2011.

[29] F. L. Lewis, H. Zhang, K. Hengster-Movric, and A. Das, "Cooperative Control of Multi-Agent Systems: Optimal and Adaptive Design Approaches," 2014.

[30] H. Liang, B. J. Choi, W. Zhuang, X. Shen, A. S. A. Awad, and A. Abdr, "Multiagent coordination in microgrids via wireless networks," IEEE Wirel. Commun., vol. 19, no. 3, pp. 14-22, 2012.

[31] R. Olfati-Saber, J. A. Fax, and R. M. Murray, "Consensus and cooperation in networked multi-agent systems," Proc. IEEE, vol. 95, no. 1, pp. 215-233, 2007.

[32] M. Mehyar, D. Spanos, J. Pongsajapan, S. H. Low, and R. M. Murray, "Distributed Averaging on Asynchronous Communication Networks," pp. 7446-7451, 2005.

[33] M. Kriegleder, "Comments and Corrections," vol. 22, no. 6, pp. 20262027, 2014. 